\title{
Yolcu Aracı Havalandırma Nozul Tasarımlarında Sızdırmazlık Problemlerine Hesaplamalı Akışkanlar Dinamiği ile Bir Mühendislik Çözümü
}

\author{
${ }^{1}$ Ekrem Altuncu, ${ }^{* 2}$ Cem Eker and ${ }^{* 3}$ Samet Kirmizitepe \\ ${ }^{1}$ Sakarya Uygulamalı Bilimler Üniversitesi, Malzeme ve Üretim Tek. Uyg.Arş. Merkezi, Sakarya, Turkey \\ *22Tasarım Depart., Tasarım Merkezi Müdürü, KNS Otomotiv, Sakarya, Turkey \\ *33Tasarım Depart., Trim Sistemler Yöneticisi, KNS Otomotiv, Sakarya, Turkey
}

\section{Özet:}

Otobüslerde, geleneksel havalandırma sistemlerinde kullanılan nozul mekanizmasında tasarım kaynaklı, geometrik tolerans değerlerinden dolayı nozul mekanizması üzerinde hava kaçakları söz konusudur. Tolerans açıklıkları hem yolcu konforu açısından problem teşkil etmekte, hem de sınırlı ölçekte nozul çalışma debisine sebep olmaktadır. Bu durum sektörde tasarım nedenli bir mühendislik problemi olup, rekabet açısından kritik öneme sahiptir. Bu problemin çözümü için; ANSYS programının hesaplamalı akışkanlar dinamiği (CFD) modülü kullanılarak hava akış analizleri yapılmıştır. Bu şekilde nozul üzerinde olan açıklıklardan geçen hava debisi ve nozul içerisinde oluşan basınç değerleri için bilgisayar destekli benzeşim çalışmaları karşılaştırmalı olarak gerçekleştirilmiştir. Farklı toleranslar için tasarım değişiklikleri üzerinde deneysel çalışmalar hava sızdırmazlık testleri ile değerlendirilmiş ve doğrulanmıştır. PROVA Avm 07 marka anemometre kullanılarak nozuldan $10 \mathrm{~cm}$ mesafede ölçüm yapıldığında müşteri konforu için $0 \mathrm{~m}^{3} / \mathrm{h}$ 'lik akışkan hızı hedefine ulaşılmıştır. Bu çalışma kapsamında tasarım kriterleri, ölçüm ve analizler karşılaştırmalı olarak analiz edilmiş ve tartışılmıştır.

Anahtar Kelimeler: Hava Kanalı, Havalandırma sistemi, Nozul tasarımı, S1zdırmazlık,

\section{An Engineering Solution to Sealing Problems in Passenger Vehicle Ventilation Nozzle Designs with Computational Fluid Dynamics}

\begin{abstract}
In the nozzle mechanism used in conventional ventilation systems used in buses, there are air leaks in the nozzle mechanism due to the geometric tolerance values caused by the design. Tolerance clearances pose a problem both in terms of passenger comfort and cause limited nozzle working flow. It is a designrelated engineering problem in this industry and is critical to competition. To solve this problem; Air flow analyzes were performed using the computational fluid dynamics (CFD) module of the ANSYS program. In this way, comparative computer-aided simulation studies were carried out for the air flow rate passing through the openings on the nozzle and the pressure values formed in the nozzle. Experimental studies on design changes for different tolerances were evaluated and validated by air tightness tests. When measuring at a distance of $10 \mathrm{~cm}$ from the nozzle using the PROVA Mall 07 anemometer, the target of $0 \mathrm{~m}^{3} / \mathrm{h}$ liquid velocity was achieved for customer comfort. In this study, design criteria, measurements and analyzes are comparatively examined and discussed.
\end{abstract}

Keywords: Air channel, Ventilation system, Nozzle design, Sealing.

*Corresponding authors: Address: KNS Otomotiv, Department of Design, 54187, Hendek OSB, Sakarya TURKEY. E-mail address: cemeker@knsotomotiv.com, Phone: + 26437801 65, Fax: 2643780161 


\section{Giriş}

Y1llar boyunca sabit sicaklık artışıyla birlikte, iklimlendirme sistemlerinin önemi gün geçtikçe artmaktadır. Araçların enerji verimliliği kadar yolcuların konforu da oldukça önem arz eden bir konu haline gelmektedir. İdeal bir otomobil iklimlendirme sistemi, termal konfor sağlamalıdır. İklimlendirme sistemleri aynı zamanda araç kalitesini doğrudan etkileyebilecek sıcaklık ve nemi azaltmakla görevlidir. Şehir içi ve şehirlerarası yolculuklarda en çok tercih edilen ulaşım araçlarından birisi otobüslerdir. Yolcu konforu için otobüs içi iklimlendirmelerin önemi büyük olduğundan otomotiv ve klima üreticileri bu konular üzerinde sürekli olarak çalışmalara yönelmişlerdir. Genel olarak otobüslerde benzer tavan tipi klima sistemleri kullanılmaktadır. Otobüs üreticileri tarafından, klimadan gelen havanın otobüs içerisinde; daha konforlu, daha düzenli bir şekilde ulaşmasını ve otobüs içerisindeki hava sirkülasyonunu sağlayan, hava kanalları üzerinde çalıșmalar yapılmaktadır. Hava kanalları; otobüsün iç kısmında olup yolcu bölmeleri üzerinde sağ ve sol üst köşelerde bulunmaktadır. Bu sistem, klima sisteminden gelen havanın, yolculara düzenli bir şekilde ulaşmasını sağlayan bir montaj ürünüdür. Minibüs, otobüs ve buna benzer farklı tip ulaşım araçlarında çeşitli türleri bulunmaktadır. Bu sistemlerde genellikler alüminyum alaşımları ve plastik malzemeler ağırlıklı olarak kullanılmaktadır [1].

KNS Otomotiv bünyesinde belirtilen özellikler dikkate alınarak hava kanalları ürünlerini ortaya koymaktadır. Firmamız bünyesine, Al 6063-T5 serisi alaşım ve ABS malzemeler tercih edilmektedir. Çünkü Alüminyum ve ABS malzemeler hava kanalları üretim prosesi için uygun malzemelerdir. Alüminyumun kolay işlenme ve şekil alabilme, yüzey kaplama çeşitliliğinin fazla olması, kolay form verilmesi, hafif bir metal olması gibi özelliklerinden dolayı tercih edilmektedir. ABS plastikleri ise geniş bir sıcaklık aralığı, kimyasal direnci, 3D yazıcı kullanarak üretilmesi, hafif bir malzeme olması, boyanabilme özelliğine sahip olması gibi avantajlara sahiptir. Aşağıdaki tabloda ABS malzemesinin kritik özellikleri sunulmaktadır $[2,3,4]$.

Tablo 1: ABS malzemenin özellikleri

\begin{tabular}{|c|c|c|c|}
\hline (ABS) özellik & BİRIM & DEĞER & METHOD \\
\hline Yoğunluk $\left(23^{\circ} \mathrm{C}\right)$ & $\mathrm{g} / \mathrm{cm}^{3}$ & $0,25-0,36$ & ASTM D185 \\
\hline $\begin{array}{l}\text { Erime Akış Hızı } \\
\left(220^{\circ} \mathrm{C}-10.0 \mathrm{~kg}\right) \\
\end{array}$ & $\mathrm{g} / 10 \mathrm{~min}$ & $0,49-36$ & ISO 1133 \\
\hline Rockwell Sertliği & - & $95-117$ & İSO 2039-2 \\
\hline $\begin{array}{c}\text { İzod Darbe Dayanımı } \\
\left(23^{\circ} \mathrm{C}\right)\end{array}$ & $\mathrm{Kj} / \mathrm{m}^{2}$ & $9,0-35,7$ & İSO 180 \\
\hline $\begin{array}{c}\text { Akmada Gerilme } \\
\text { Dayanımı }\end{array}$ & $\mathrm{MPa}$ & $35,9-63,5$ & İSO 527-2 \\
\hline $\begin{array}{c}\text { Kopmada Gerilme } \\
\text { Dayanımı }\end{array}$ & $\mathrm{MPa}$ & $29-42$ & İSO 527-2 \\
\hline Erime Noktası & ${ }^{\circ} \mathrm{C}$ & 218 & \\
\hline Bükülme Mod $\left(23^{\circ} \mathrm{C}\right)$ & $\mathrm{MPa}$ & $1860-2860$ & İSO 178 \\
\hline Camsı Geçiş Sıcaklığı & ${ }^{\circ} \mathrm{C}$ & 104 & ISO $11357-22$ \\
\hline
\end{tabular}

Hava kanalları birçok bileşenden meydana gelmektedir. Hava kanallarının içinde barındırdığı sistemlerden bir tanesi de servis setleri adı verilen üründür. Servis setleri ise kendi içerisinde yine birçok bileşenden meydana gelmektedir. Bunların içerisinde plastik enjeksiyon kullanılarak üretilen malzemeler vardır. Bu malzemelerden birisi olan nozul havalandırma 
sistemleri için kritik bir üründür. Nozul parçalar müşterilerin özel istekleri dikkate alınarak tasarlanmaktadır. Modelleme işlemi tasarım merkezimiz tarafınca yapılmaktadır. Tasarım, nozul parçaların üretilmesi için kalıp tasarımının çalışması ile başlamaktadır. Nozul üretimini sağlayacağımız kalıp; tesisimizde CNC işleme tezgahlarında üretilip, toplandıktan sonra plastik enjeksiyon makinasına yerleştirilmektedir. Nozul üretiminde kullanılan malzeme; ABS adı verilen; akrilonitril bütadien stiren içeren bir polimer malzemedir. İçerisine pigment eklenerek istenen renklere ulaşılmaktadır. ABS malzeme nozul üretiminde $220{ }^{\circ} \mathrm{C}$ sıcaklıkta işleme tabi tutulmaktadır.

Plastik parça imalatında üretimden önceki son adım tasarlanan parça ve kalıba göre plastik enjeksiyon makinasının seçimini yapmaktır. Plastik enjeksiyon makinasının özellikleri, maksimum proses şartlarını sağlayabilecek şekilde seçilmektedir. Temelde kapalı bir kalıbın içine plastik malzemenin eriyik sıcaklığının üstündeki bir sıcaklık aralığında yüksek hızda yolluk girişinden kalıp gözüne hızlı bir şekilde enjekte edilmesi sonrasında ütüleme fazı ve tutma fazı ile parçanın boyut ve görsel toleransının kabul edilebilir seviyeye getirildikten sonra plastiğin kalıptan çıkarılması prensibine dayanan bir plastik parça imalat yöntemidir. Bir plastik ürünün meydana gelmesinde süreç parça tasarımıyla başlamaktadır. Plastik parça tasarımı yapılırken tasarımcı parçanın fonksiyonelliğine, işletme şartlarına ve maliyetine göre hangi hammaddeyi kullanacağını belirlemelidir. Bir sonraki adım plastik parçanın enjeksiyon makinasında basılacağı kalıbın tasarımıdır. Günümüzde plastik kalıpları proses verimliliğini arttırıcı bir çok elemandan oluşmaktadır, burada önemli olan kalıp maliyetlerini çok yükseltmeden verimli bir imalat süreci geçirecek şekilde kalıbın tasarlanmasıdır [5].

Üretilen nozullar, üretim sonrasında test merkezimiz bünyesinde yapılan sızdırmazlık testine tabi tutulmaktadır. Elde edilen deneysel çalışmalar sonucunda nozul ürünlerinde hava kaçağı tespit edilmiştir. Hava kaçağının olması, araç içerisinde seyahat eden müşterinin konfor alanını bozmaktadır. Aynı zamanda araç içerisindeki gerekli olan hava sirkülasyonu veya iklimlendirme işlemlerinin gerçekleşmesinde problem teşkil etmektedir. Ürünün hava kaçağ1 olması kalite problemlerini de beraberinde getirmektedir. Elde edilen verilerin doğuracağı bu sonuçların önüne geçmek için geriye dönük çalışmalar yapılmalı, tasarım girdileri kontrol edilmelidir. Hata sebebinin tespit işleminden sonra düzeltilmesi, ürün kullanım amacına uygun fonksiyonunun yerine getirilmesi sağlanmalıdır. Geriye dönük yapılan çalışmalar incelendiğinde, hava kaçağı sebebinin tasarımdan kaynaklı olduğu tespit edilmiştir. Hava kaçağ1 ürünün geometrik tolerans değerinden kaynaklanmaktadır. Bu durum hem yolcu konforunu düşürmekte hem de sınırlı ölçekte nozul çalışma debisine sebep olmaktadır. Oluşan bu problem, sektörde tasarım nedenli bir mühendislik problemi olup, rekabet açısından kritik öneme sahiptir.

\section{Test ve Metot}

Üretilen nozul parçaların kontrolleri ve testler firmamız bünyesinde bulunan test merkezimizde yapılmaktadır. Üzerinde nozuların olduğu hava kanalları sistemine hava çıkış boruları bağlanır. Aktif hale getirilen cihazdan nozullara hava akışı sağlanır. Testin gerçeklemesi gereken değerler sisteme girilir. Standartlar gereği istenilen hava debisi; 5000

$\mathrm{m}^{3} / \mathrm{h}$ 'dir. Toplam test süresi, 15 dakikadan oluşmaktadır. Sızdırmazlık testinin yapılabilmesi 
için gereken cihazın tasarımı ve üretimi tasarım merkezimize aittir. Sızdırmazlık test sisteminde, havalandırma borularından hava kanalına akış sağlama prensibine dayanmaktadır. Hava kanalı üzerine servis seti montajı yapılarak içerisinde nozullar yerleştirilmiştir. Hava akışı aktif hale getirilerek test başlatılmıştır. Sızdırmazlık test cihazı aşağıdaki şekilde görülmektedir.

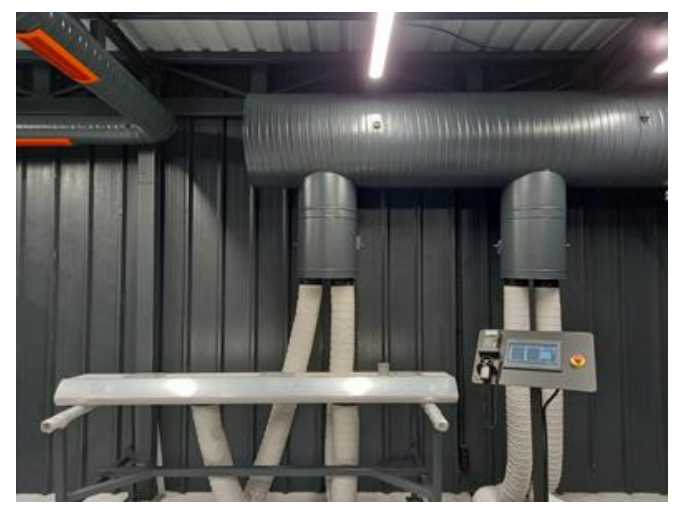

Şekil 1: Sızdırmazlık test ölçüm cihazı.

Sızdırmazlık ölçümünün yapılabilmesi için gerekli diğer ekipmanlar; elde edilen debi değerini ölçmemizi sağlayan anenometre cihazı ve değerlerin girilebilmesini aynı zamanda sonuçların görülebilmesini sağlayan panodan oluşmaktadır. Test standartlarına göre anenometre cihazı nozullardan $10 \mathrm{~cm}$ yukarıda olacak şekilde tutulması gerekmektedir. Elde edilen debi değerleri kayıt edilmektedir. Aşağıdaki şekilde metre yardımı ile anenometrenin mesafesinin ayarlanması ve cihazdaki hava debisi ölçümü görülmektedir.
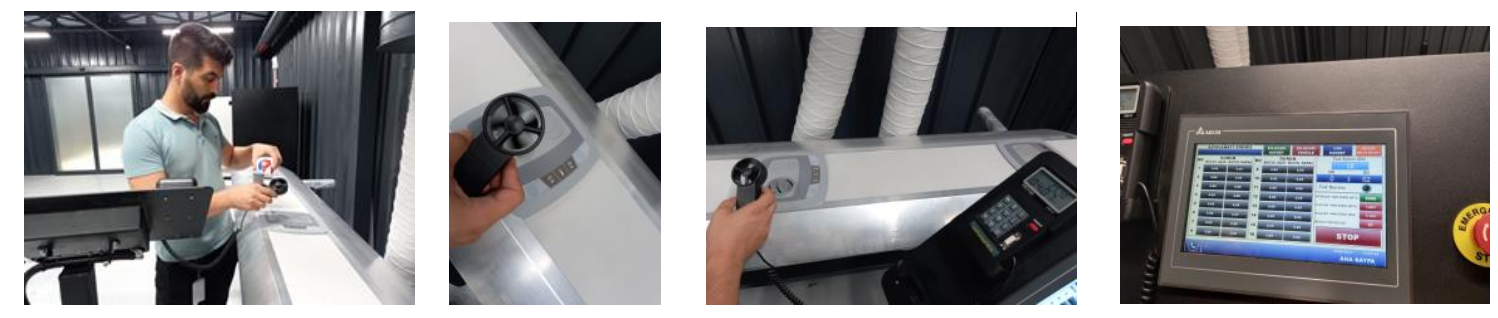

Şekil 2: Gerekli mesafenin ayarlanması ve hava debisi değerlerinin ölçülmesi.

Elde edilen veriler sonucunda hava debisi; $2-4 \mathrm{~m}^{3} / \mathrm{h}$ arasında değerlere ulaşmaktadır. Bu değer müşteri özel isteklerindeki normlara göre kabul edilebilir aralıkta değildir. Aşağıda bulunan şekilde anenometre ile yapılan ölçüm görsel olarak sunulmaktadır. 

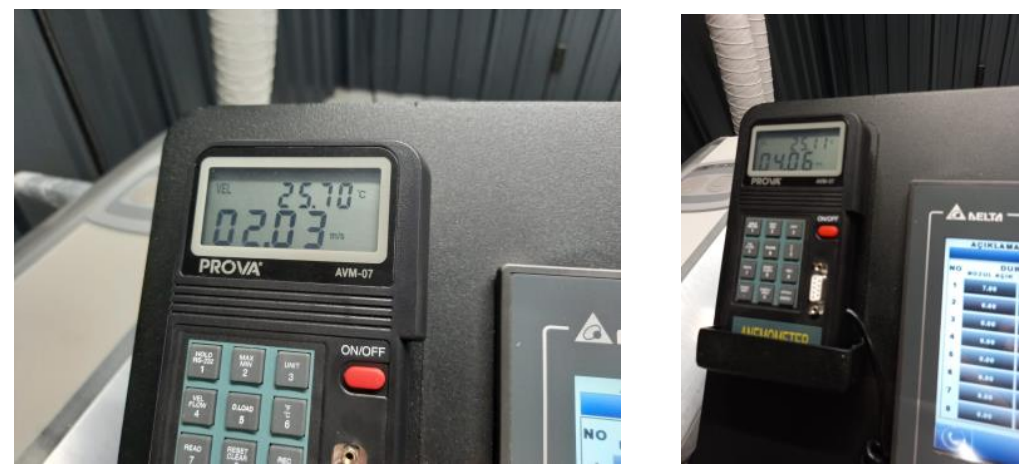

Şekil 3: Hava debisi ölçüm sonuçları görseli.

$\mathrm{Bu}$ yüzden geçmiş çalışmalara dönülerek, yüksek hava debisinin hangi parametreler sonucunda ortaya çıkabileceği ve bu sorunların önüne nasıl geçilebileceğine dair kapsamlı bir çalışma yapılmıştır. Elde edilen sonuçlara göre tasarım geometrisinde revizyon çalışması yapılmasına karar verilmiştir. Mevcut nozul içerisine bir klape yerleştirilerek tekrar tasarım çalışması yapılmıştır. Tasarım revizyonunun teknik modelleri aşağıdaki şekilde sunulmaktadir.
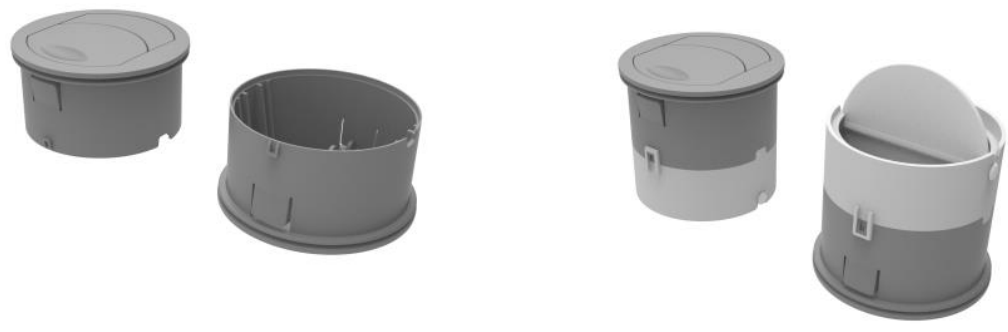

Şekil 4: Tasarımda revizyonu yapılan nozul parçalarının görüntüsü

Bu problemin çözümü için; ANSYS programının hesaplamalı akışkanlar dinamiği (CFD) modülü kullanılarak hava akış analizleri yapılmıştır. Bu şekilde nozul üzerinde olan açıklıklardan geçen hava debisi ve nozul içerisinde oluşan basınç değerleri için bilgisayar destekli simülasyon çalışmaları karşılaştırmalı olarak gerçekleştirilmiştir. Programdan elde edilen sonuçlar aşağıdaki şekilde mevcuttur. Aşağıdaki şekillerde klapesiz nozul analiz sonuçları görülmektedir.
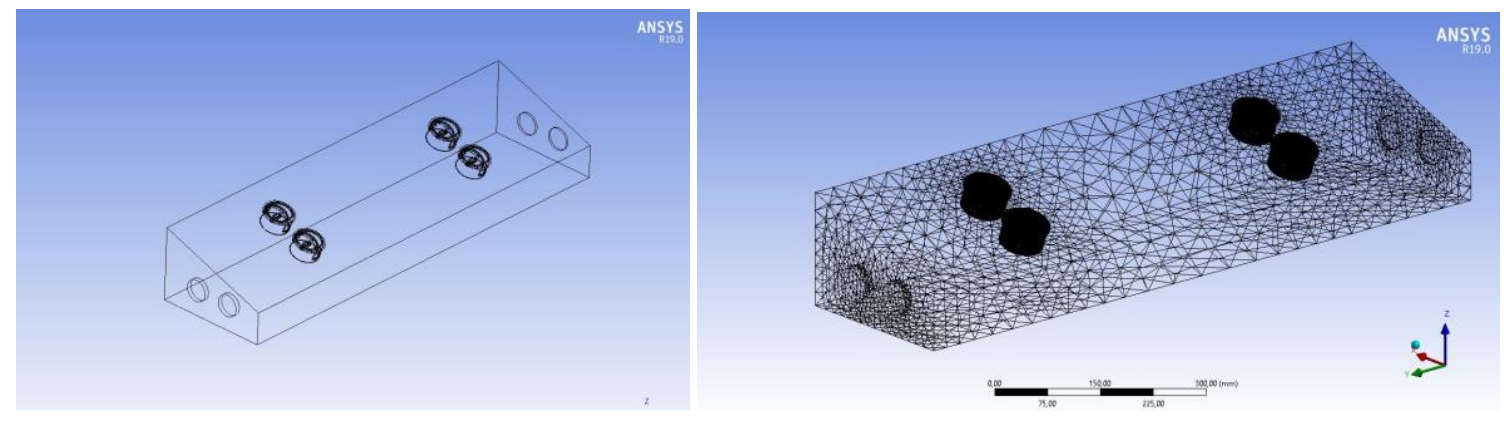

Şekil 5: Analizi yapılan klapesiz nozul simülasyon tasarımı ve mesh görüntüsü. 
Analizi yapabilmemiz için mesh işlemi yapılarak, geometrik elemanlarımız düğümlere ve noktalara ayrılmaktadır. Herhangi bir geometri üzerinde sonsuz sayıda nokta ve eleman vardır. Geometriler üzerinde çözüm yapabilmemiz için, geometrimizi belirli sayıda eleman ve noktalara ayırmamız gerekir. Sonlu Elemanlar yöntemi ile parça modellenirken, model küçük parçalardan oluşan temel elemanlara ayrılır. Buna mesh işlemi denir. Her elemanın köşelerinde dügüümler (node) vardır. Hesaplamalar bu düğüm noktaları üzerinde gerçekleştirilmektedir. Dolayası ile fiziksel ortam önce elemanlara (element) bölünür ve elemanların köşe noktaları ise fiziksel ortamı temsil eden noktalar uzayı olmuş olur. Elde edilen sonuçlar bu noktaların üzerindeki değerlerdir.

\section{Sonuçlar ve Tartışma}

Aşağıdaki görsellerde belirtildiği üzere analiz sonuçlarına göre; nozulda klape olmadığı için hava akışı nozulun iç tarafına doğru geldiğinden nozul yaprakları arasındaki mekanik toleranslara göre hava kaçakları gözlemlendiği tespit edilmiştir. Hava kanalı içerisinde bulunan havanın basıncına göre nozulların iç taraflarının hava kanalı ile aynı basınca sahip olması, hava akışının nozulun iç tarafına geldiğini ispat etmektedir.
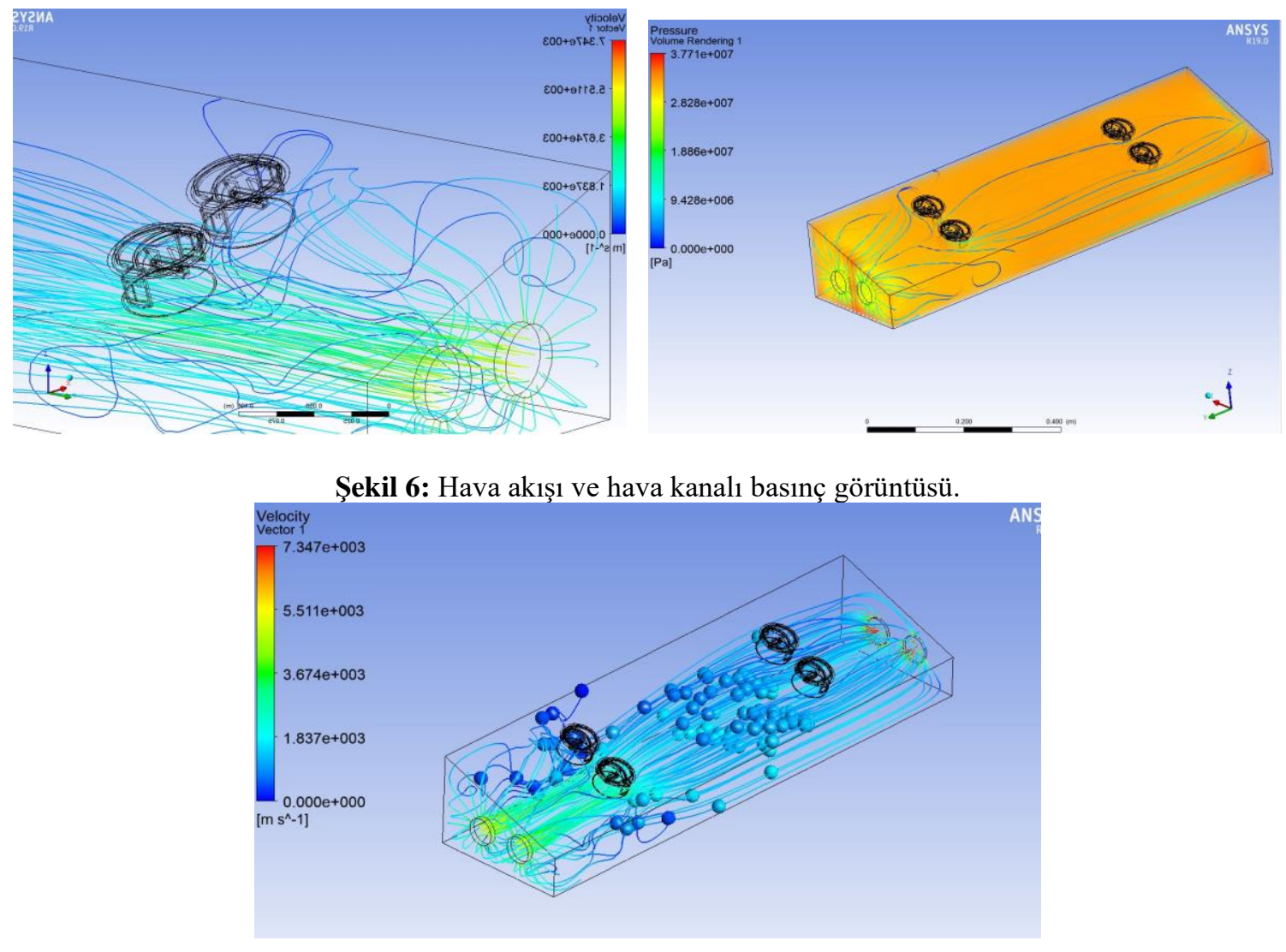

Şekil 7. Hava akış kabarcıklarının görüntüsü.

Aşağıdaki şekillerde revizyon sonrasında klape eklendikten sonra üretilen nozulun ANSYS programından elde edilen verilerinin görselleri bulunmaktadır. 

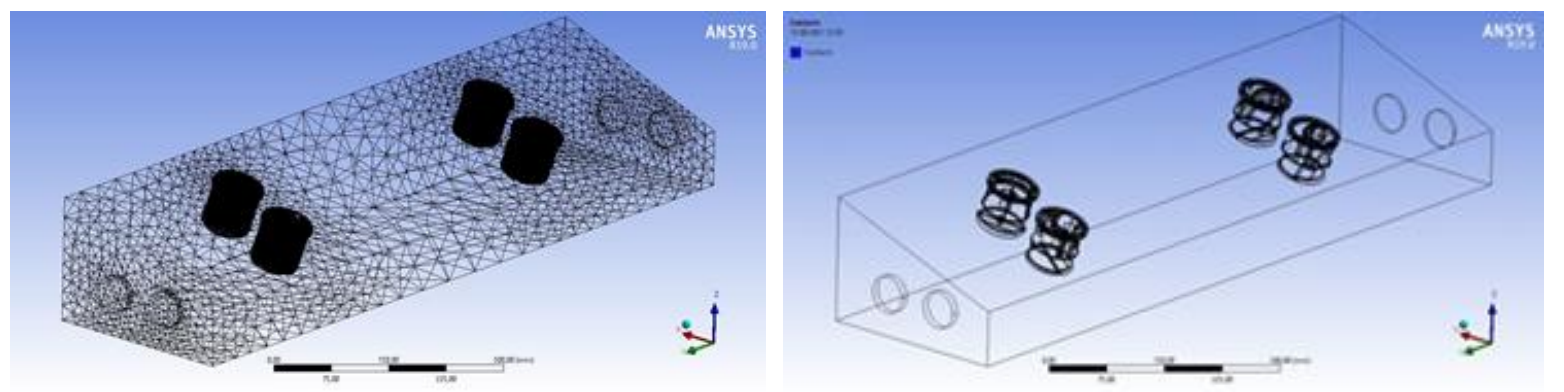

Şekil 8: Analizi yapılan klapeli nozul simülasyon tasarımı ve mesh görüntüsü.

Çalışmanın ilk aşamasında, klapeli malzemeli sepetlik modeli için ANSYS programından mesh çalışması yapılmıştır.
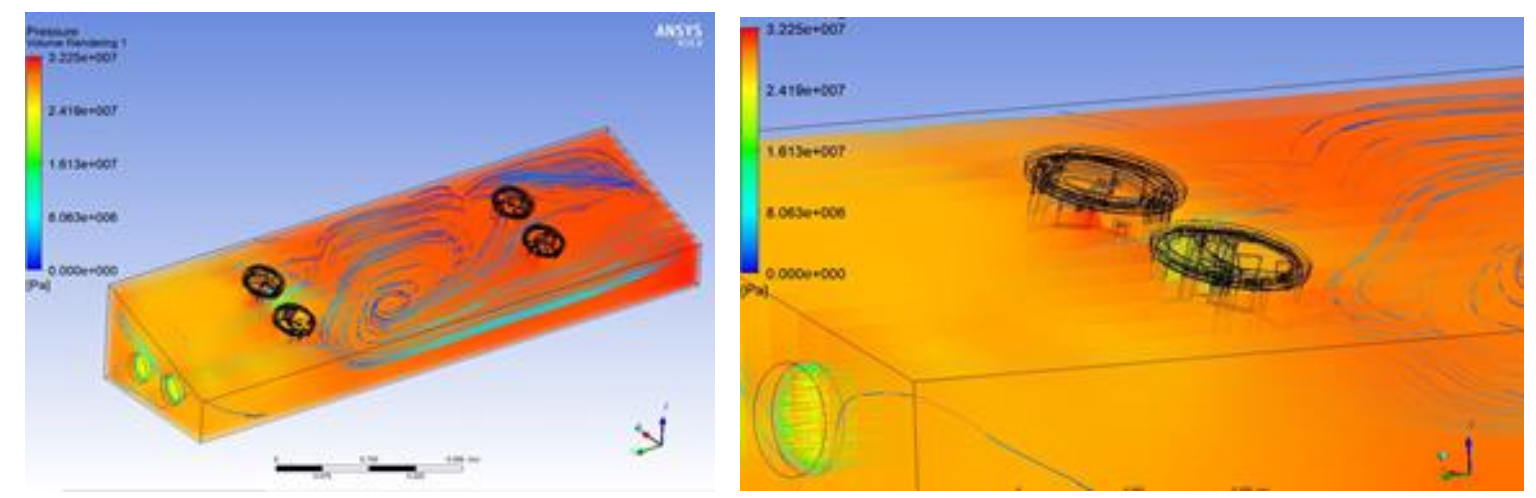

Şekil 9 : Klapeli nozulun hava kanalının içerisindeki basınç görünümü.
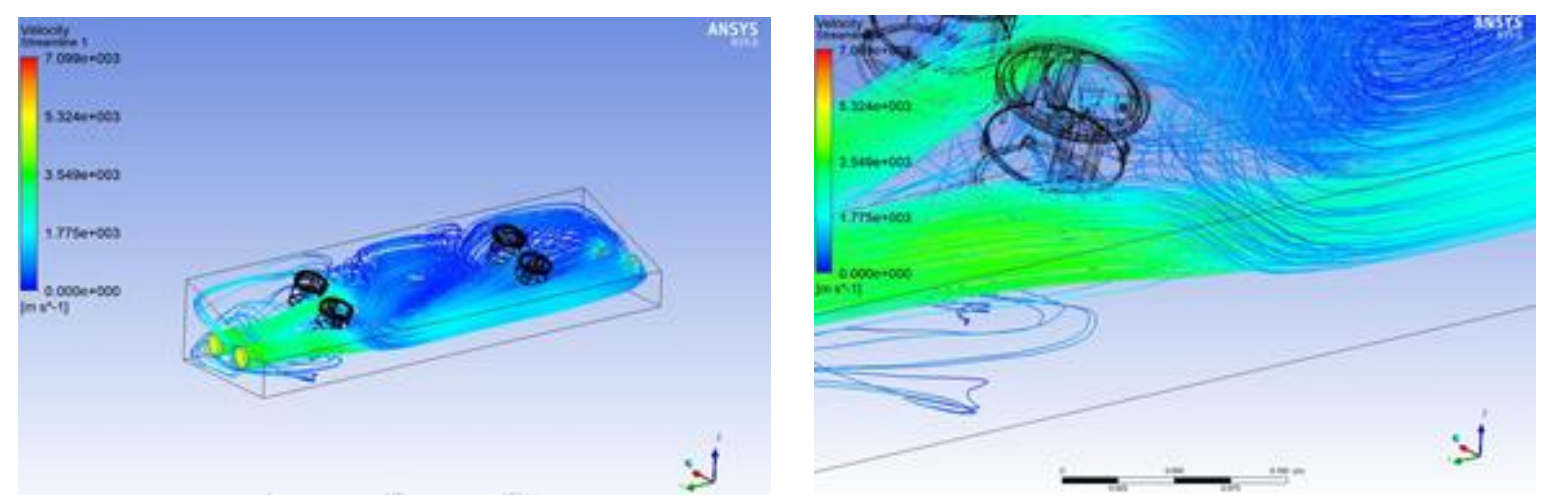

Şekil 10 : Klapeli nozul hava akış görüntüsü.

Şekil 9'da bulunan hava kanalı içerisindeki basınca göre nozulların içerisinde hava basıncı olmadığı yani 0 Pascal olduğu tespit edilmiştir. Bu durum hava nozullarının içerisine hava girmediğini kanıtlar niteliktedir. Şekil 10'da bulunan; analiz sonuçalarına göre nozula revizyon olarak yapılan klape sayesinde hava akışının nozul içerisine girmesi engellenmiş olduğu görülmektedir. 


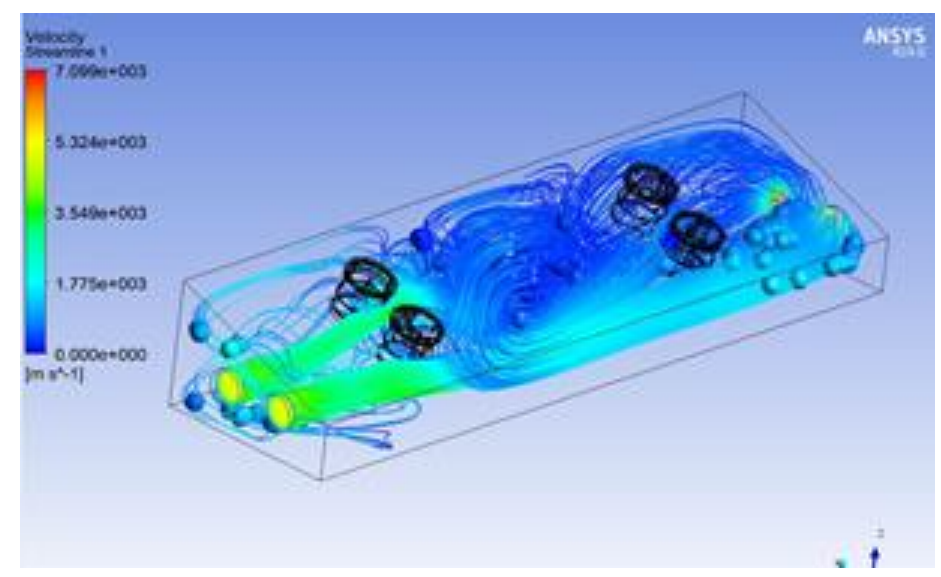

Şekil 11: Klapeli hava akış kaparcıklarının görüntüsü.

Müşteri konforu için $0 \mathrm{~m}^{3} / \mathrm{h}$ 'lik akışkan hızı hedeflenmiştir. Tasarım revizyonu ANSYS programından elde edilen sonuçlara göre; nozullar, klapeli olarak tekrar üretilip, firmamız bünyesine bulunan test merkezinde analizleri yapılmıştır. Test için nozullar servis setine aşağıdaki şekilde konumlandırılmıştır.

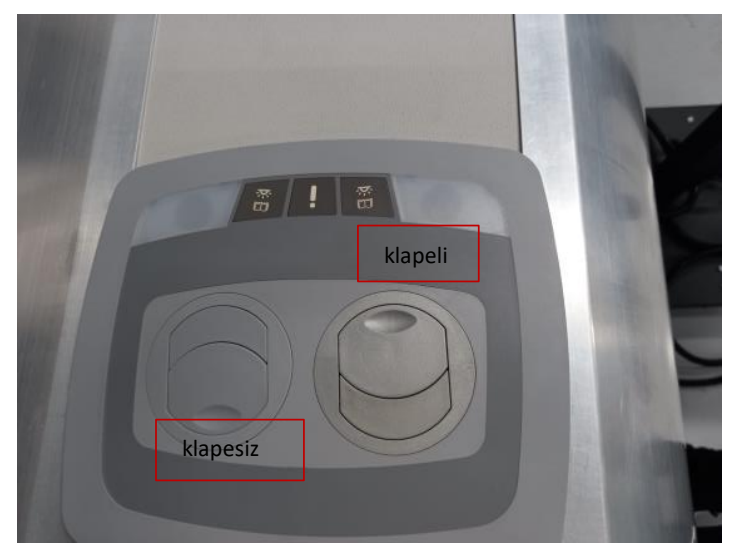

Şekil 12: Test cihazına nozullerin konumlandırılması.

Elde edilen hava debisi; 0,0-0,56 $\mathrm{m}^{3} / \mathrm{h}$ arasında ölçüm değerine ulaşılmışıtr. $\mathrm{Bu}$ değerler istenilen kriterlerin sağlanabilmesi ve hedefimiz için uygun değerlerdir. Aşağıdaki şekilde tasarım sonrasında yapılan revizyon işleminden elde edilen değerler sunulmaktadır. 

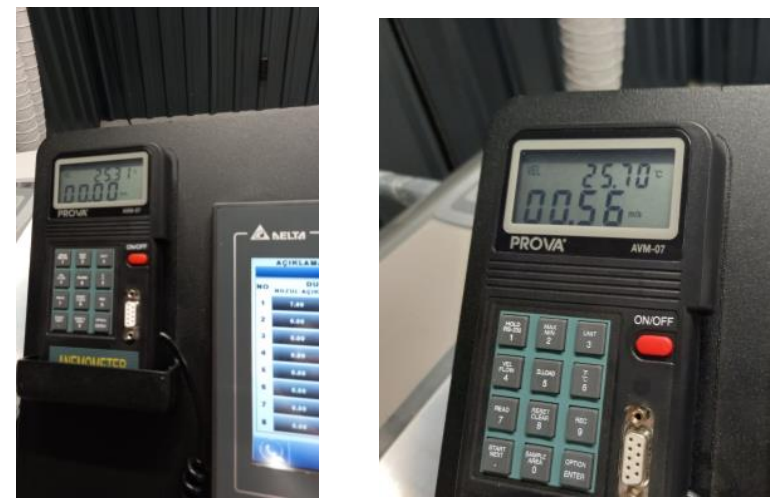

Şekil 13: Hava debisi ölçüm sonuçları görselinin görüntüsü.

\section{Genel Sonuçlar}

PROVA Avm 07 marka anemometre kullanılarak nozuldan $10 \mathrm{~cm}$ mesafede ölçüm yapıldığında müşteri konforu için $0 \mathrm{~m}^{3} / \mathrm{h}$ 'lik akışkan hızı hedefine yaklaşılarak ulaşılmıştır. Bu çalışma kapsamında tasarım kriterleri, ölçüm ve analizler karşılaştırmalı olarak analiz edilmiş ve tartışılmıştır. Aşağıdaki tabloda yapılan testlerde hava debisi ölçüleri karşılaştırmalı olarak sunulmaktadır. Elde edilen verilere göre yapılan revizyon çalışması sonuçlarında da gözle görülebilen iyileştirme sonuçları elde edilmiştir.

Aşağıdaki tabloda klapeli ve klapesiz nozul tasarımları karşılaştırmalı olarak incelenmiştir. Elde edilen sonuçları göre klape eklenerek revizyon edilen tasarım çalışmasının sonucunda istenilen değerlere ulaşılmıştır. Hava debisi; 2-4 $\mathrm{m}^{3} / \mathrm{h}$ 'den, klape eklendikten sonra $0-0,5 \mathrm{~m}^{3} / \mathrm{h}$ 'ye değerlerine ulaşılması sağlanmıştır. Hedeflenen değere ulaşılması ile araç içerisinde hava sirkülasyonu sağlanacaktır. Aynı zamanda iklimlendirme fonksiyonlarının gerektiği gibi çalışması da sağlanacaktır. Böylece ürün kalitesini arttırarak, müşteri memnuniyetini de beraberinde getirecek bir çalışma niteliğindedir. Tablo 2'de klapeli nozul ve klapesiz nozulların karşılaştırmalı sonuçları sunulmaktadır.

Tablo 2: Nozula uygulanan testler sonrası debi karşılaştırmaları.

\begin{tabular}{|c|c|c|}
\hline Nozul (hava kaçağı) Test & $\begin{array}{c}\text { Klapesiz nozul } \\
\text { (revizyon öncesi) }\end{array}$ & $\begin{array}{c}\text { Klapeli Nozul (revizyon } \\
\text { sonrası) }\end{array}$ \\
\hline Debi $\left(\mathbf{m}^{3} / \mathbf{h}\right)$ & $2-4$ & $0-0,5$ \\
\hline
\end{tabular}

$\mathrm{Bu}$ çalışmanın yürütülmesinde ve test olanaklarının sağlanmasında yardımlarını ve emeklerini esirgemeyen KNS Otomotiv Tasarım Merkezine ve KNS Otomotiv Test Merkezine teşekkürlerimizi sunarız. 


\section{Kaynakça}

[1] Elshad V., Vahdet UÇAR.. Elektrikli Otobüsler İçin Hava Kanalları Tasarımı Ve Cfd Yöntemi İle Akış Analizi. MAS Journal of Applied Sciences, 2021. 422-432.

[2] Nuri Ş., Ömer Ş.,İlyas U. Geri Dönüşümü Yapılmış PP ve ABS Prototip Malzemelerin Bazı Mekanik ve Termal Özelliklerinin İncelenmesi, 2020.

[3] Hatice E., Gülçin E., Elif Y. Açık ve Kapalı Sistemlerde Doluluk Oranının Parça Mukavemetine Etkisinin İncelenmesi. Journal of Polytechnic,2018. 651-662

[4] Teknik Bilgi Hazinesi. www. http://teknikbil.blogspot.com/, 29.07.2021

[5] Engin Pınar. Plastik Enjeksiyon Yöntemiyle İmalatta Hataların Tespiti Ve Proses Şartlarının Optimizasyon Uygulaması. Yüksek Lisans. Makine Mühendisliği. İstanbul Yıldız Teknik Üniversitesi, 2010. 